\title{
PENGARUH PENYULUHAN TENTANG MENOPAUSE TERHADAP TINGKAT KECEMASAN IBU DALAM MENGHADAPI MENOPAUSE DI KELURAHAN TOBOLEU KECAMATAN KOTA TERNATE UTARA
}

\author{
THE EFFECT OF EXTENSION ABOUT MENOPAUSE ON THE MOTHER'S \\ ANXIETY LEVEL IN FACING MENOPAUSE IN THE TOBOLEU \\ DISTRICT, SUBDISTRICT OF TERNATE UTARA CITY
}

\author{
Sitti Hubaya Matjino \\ Program Studi Diploma III Kebidanan Politeknik Kesehatan Kementerian Kesehatan Ternate \\ Korespondensi: sittimatjino@gmail.com
}

\begin{abstract}
A premenopausal syndrome is experienced by many women almost all over the world, around 70-80\% of European women, 60\% in America, 57\% in Malaysia, 18\% in China and 10\% in Japan and Indonesia (Urnobasuki, 2010). According to WHO, every year around 25 million women around the world experience menopause. Indonesian women generally begin to experience premenopausal age at 40-50 years. Menopause experienced by women often causes anxiety. This study aims to determine the effect of counseling about menopause on maternal anxiety levels in the face of menopause in Tobeleu Sub-District, North Ternate City in 2018

This type of research uses quasi-experimental research with one group pre-post test design The population in this study were all mothers aged 45-50 years who had not experienced menopause as many as 35 people. The type of sampling is purposive sampling technique. Data analysis used univariate analysis and paired sample t-test.

The level of maternal anxiety before being given counseling about menopause mostly shows the level of severe maternal anxiety as many as 14 people (40.0\%), the level of maternal anxiety after being given counseling about menopause most of the mothers did not experience anxiety/panic as many as 16 people (45.7\%), there is an effect of counseling about menopause on the level of anxiety of mothers facing menopause ( $p$-value $0,000<\alpha=0.05$ ).

Women need to think positively in the face of the menopause phase. That is more because it will produce positive actions that will increase the degree of health of women in old age.
\end{abstract}

Keywords $\quad$ : Mother's Anxiety Level, Facing Menopause

\begin{abstract}
ABSTRAK
Sindrom premenopause dialami oleh banyak wanita hampir di seluruh dunia, sekitar 70-80\% wanita Eropa, 60\% di Amerika, 57\% di Malaysia, 18\% di Cina dan 10\% di Jepang dan Indonesia (Urnobasuki, 2010). Menurut WHO, setiap tahunnya sekitar 25 juta wanita di seluruh dunia
\end{abstract}


mengalami menopause. Umumnya perempuan Indonesia mulai mengalami masa premenopause pada usia 40-50 tahun. Menopause yang dialami wanita seringkali menimbulkan kecemasan. Penelitian ini bertujuan mengetahui pengaruh penyuluhan tentang menopause terhadap tingkat kecemasan ibu dalam menghadapi menopause di Kelurahan Tobeleu Kecamatan Kota Ternate Utara Tahun 2018. Jenis penelitian ini menggunakan Penelitian quasi experimental dengan one group pre test -post test design Populasi dalam penelitian ini adalah semua ibu yang berusia 4550 tahun yang belum mengalami menopause sebanyak 35 orang. Jenis pengambilan sampel yaitu teknik purposive sampling. Analisis data menggunakan analisis univariat dan uji $\mathrm{t}$ sampel berpasangan.

Tingkat kecemasan ibu sebelum diberikan penyuluhan tentang menopause sebagian besar menunjukkan tingkat kecemasan ibu berat sebanyak 14 orang (40,0\%), tingkat kecemasan ibu setelah diberikan penyuluhan tentang menopause sebagian besar tidak ada ibu yang mengalami kecemasan/ panik sebanyak 16 orang $(45,7 \%)$, ada pengaruh penyuluhhan tentang menopause terhadap tingkat kecemasan ibu menghadapi menopause ( $\mathrm{p}$ value $0,000<\alpha=0,05$ ). Penting bagi wanita untuk berpikir positif dalam menghadapi fase menopause. Hal itu lebih dikarenakan akan menghasilkan tindakan positif yang akan meningkatkan derajat kesehatan wanita di usia lanjut.

\section{Kata kunci: Tingkat Kecemasan Ibu, Menghadapi Menopause}

\section{PENDAHULUAN}

Proses penuaan telah terjadi sejak manusia dilahirkan ke dunia, dan proses ini terjadi secara terus-menerus sepanjang kehidupannya sesuai dengan hukum alam. Secara khusus pada perempuan, proses penuaan ini mempunyai dampak tersendiri terhadap siklus haidnya. Siklus haid tersebut setiap bulannya akan mulai terganggu dan akhirnya menghilang sama sekali (Purwoastuti, 2008).

Fase ini terjadi karena perempuan tidak lagi menghasilkan esterogen yang cukup untuk mempertahankan jaringan yang responsive dalam suatu cara yang fisiologi.
Akibat dari kadar hormon esterogen, progerseteron dan hormon ovarium yang berkurang akan menyebabkan perubahan fisik, psikologis dan seksual yang menurun pada perempuan pasca menopause.

Pre menopause adalah suatu masa peralihan antara tahun-tahun reproduktif akhir dan menopause sebenarnya yang dimulai pada akhir masa reproduksi, terjadi pada usia 40 tahun keatas (Purwoastuti, 2008). Fase ini ditandai dengan siklus haid yang tidak teratur, dengan perdarahan haid yang memanjang dan jumlah darah haid yang relative banyak. Sedangkan menopause adalah fase dimana wanita mendapatkan 
haid alami yang terakhir, dimana terjadi antara usia 45-55 tahun (Retnowati S, 2010). Menopause dikenal sebagai masa berakhirnya menstruasi atau haid, dan sering dianggap menjadi hal yang menakutkan dalam kehidupan wanita. Sebagian besar wanita mulai mengalami gejala menopause pada usai 40-an dan puncaknya tercapai pada usia 50 tahun. Walaupun bukan suatu penyakit, peristiwa ini mempunyai dampak dalam kehidupan wanita terutama bagi wanita yang banyak aktifitas, sehingga dapat dirasakan sebagai suatu gangguan fisik maupun psikis (Wirakusumah, 2013)

Penyuluhan pada wanita premenopause yang dilakukan oleh tenaga medis dengan cara memberikan informasi mengenai Pengetahuan tentang menopause sangat penting bagi perempuan yang akan memasuki masa tersebut. Karena pada masa ini terjadi banyak perubahan baik dari fisik maupun psikologis. Perempuan yang memiliki pengetahuan baik maka akan menyikapi dengan positif, namun jika pengetahuan kurang maka akan menyikapinya dengan banyak keluhan.

Sindrom premenopause dialami oleh banyak wanita hampir di seluruh dunia, sekitar 70-80\% wanita Eropa, 60\% di Amerika, 57\% di Malaysia, 18\% di Cina dan
10\% di Jepang dan Indonesia (Urnobasuki, 2010). Menurut WHO, setiap tahunnya sekitar 25 juta wanita di seluruh dunia mengalami menopause. Umumnya perempuan Indonesia mulai mengalami masa premenopause pada usia 40-50 tahun. Menopause yang dialami wanita seringkali menimbulkan kecemasan.

Menurut Abbottabad (2010) dalam studinya di Pakistan, telah menemukan bahwa $78,79 \%$ perempuan sadar tentang menepouse, sisanya $21,21 \%$ tidak sadar. Sedangkan $15,87 \%$ memiliki pengetahuan tentang gejala dan implikasi kesehatan menopause, sisanya $84,13 \%$ tidak. Kebanyakan perempuan yang tidak sadar tentang menopause ini tidak berpendidikan dan memiliki ekonomi yang rendah.

Menurut Depkes RI (2009) hingga saat ini wanita Indonesia yang memasuki masa menopause sebanyak $7,4 \%$ dari populasi. Jumlah tersebut meningkat menjadi $11 \%$ pada 2005 . Kemudian, naik lagi sebesar $14 \%$ pada 2015. Meningkatnya jumlah tersebut, sebagai akibat bertambahnya populasi penduduk usia lanjut dan tingginya usia harapan hidup bersamaan dengan membaiknya derajat kesehatan masyarakat. Jumlah dan proporsi penduduk perempuan yang berusia diatas 50 tahun dan 
diperkirakan memasuki usia menopause dari tahun ke tahun juga mengalami peningkatan yang sangat signifikan. Berdasarkan data dari Riset Kesehatan Dasar Indonesia pada tahun 2013 jumlah penduduk menurut jenis kelaminnya setiap tahun mengalami peningkatan dari tahun 2010 sampai 2013. Pada tahun 2010 terdapat 118.010.413 penduduk perempuan, tahun 2011 sebesar 119.768.768 penduduk perempuan, tahun 2012 sebesar 121.553.332 penduduk perempuan dan pada tahun 2013 sebesar 123.364.472 (Depkes, 2013)

Studi Ikatan Dokter Indonesia bekerjasama dengan Fakultas Kedokteran Universitas Indonesia menyebutkan bahwa $34 \%$ wanita Indonesia mengalami gejala kecemasan dalam menghadapi menopause. Sebuah penelitian di Kabupaten Sleman pada tahun 2015 menyebutkan bahwa wanita pada usia premenopause sebanyak $86,67 \%$ mengalami kecemasan dalam katagori sedang. (Nusantoro, 2015). Penelitian lain menyebutkan sebanyak 39,4\% dari 71 wanita mengalami kecemasan dalam katagori berat. Salah satu faktor penyebabnya adalah kurangnya pengetahuan mengenai menopause (Isyana, 2017).

Ketika wanita sudah memasuki usia 45 sampai 55 tahun, mulai kurang memperhatikan keseimbangan tubuhnya. Saat muda, perempuan sangat memperhatikan gaya hidup, pola makan, keseimbangan berat badan, dan kecantikan kulit. Tetapi pada usia tersebut mulai tidak mempedulikan aturan-aturan diet dan sebagainya (Lestary D, 2010). Dan pada masa ini wanita akan merasa khawatir akan perubahan yang terjadi pada tubuhnya. Kekhawatiran ini mungkin berawal dari pemikiran bahwa dirinya akan menjadi tidak sehat, tidak bugar, dan tidak cantik lagi. Kondisi tersebut memang tidak menyenangkan dan menyakitkan. Munculnya kekhawatiran yang berlebihan itu menyebabkan mereka sulit menjalani masa ini (Kasdu, 2002).

Studi pendahuluan yang dilakukan pada bulan Juli 2018 di Kelurahan Tobeleu Kecamatan Kota Ternate Utara menunjukkan dari $25 \mathrm{ibu}$ yang ditemui menyatakan bahwa 17 ibu mengalami kecemasan menghadapi menopause dan 8 ibu menyatakan belum paham tentang menopause. Berdasarkan informasi dari masyarakat di Kelurahan Toboleu belum pernah dilakukan penyuluhan terkait Kesehatan Reproduksi khusunya tentang menopause, hal tersebut juga dibenarkan oleh tenaga kesehatan dari puskesmas 
terdekat. Kecemasan yang dialami oleh ibu rata-rata akibat kurangnya pengetahuan ibu mengenai masa menopause, dan pengaruh sosial ekonomi. Berdasarkan data yang diperoleh menunjukkan bahwa angka kecemasan menghadapi menopause masih tinggi, sehingga peneliti tertarik melakukan penelitian dengan judul “ Pengaruh Penyuluhan Tentang Menopause terhadap Tingkat Kecemasan Ibu dalam Menghadapi Menopause di Kelurahan Tobeleu Kecamatan Kota Ternate Utara ".

\section{METODE}

Penelitian ini menggunakan penelitian quasi experimental dengan one group pre test post test design Proses penelitian ini dilakukan selama 5 (lima) bulan dimulai dari survey pendahuluan sampai dengan pelaporan pada bulan Agustus sampai Desember 2018 di Kelurahan Tobeleu Kecamatan Kota Ternate Utara. Populasi dalam penelitian ini adalah semua ibu yang berusia 35-45 tahun yang belum mengalami menopause. Sampel pada penelitian ini adalah ibu yang berusia 35-45 tahun yang belum mengalami menopause sebanyak 35 orang. teknik pengambilan sampel secara sengaja ditentukan sendiri oleh peneliti dengan kriteria inklusi dan eksklusi pengambilan data diperoleh dengan cara melakukan wawancara langsung terhadap responden dengan berpedoman pada kuesioner yang telah tersedia yang memuat pertanyaan-pertanyaan maupun pernyataanpernyataan yang digunakan untuk menggali informasi mengenai variabel-variabel yang akan dianalisis pada penelitian ini yang erat kaitannya dengan tingkat kecemasan ibu dalam menghadapi menopause dan melalui instansi terkait yaitu meminta dokumen dokumen yang dimiliki oleh Kelurahan Tobeleu Kecamatan Kota Ternate Utara terkait jumlah ibu yang berusia antara 45-50 tahun. Analisis data di dapatkan dengan menggunakan analisis univariat dengan cara mendeskripsikan tiap-tiap variabel yang digunakan dalam variabel ini, yakni dengan melihat gambaran distribusi frekuensi serta persentase tunggal yang terkait dengan tujuan penelitian dan analisis bivariat dilakukan untuk mengetahui hubungan variabel dependen dan independen dalam bentuk tabulasi silang (crosstab) dengan menggunakan sistem kumputerisasi program SPSS (Statistical Package for Social Sciences). Data dari kelompok perlakuan tersebut dianalisis normalitasnya dengan uji saphiro wilk. Hasil analisis normalitas didapatkan distribusi data yang normal atau tidak normal. Setelah diketahui data normal 
maka selanjutnya menggunakan rumus uji t sampel berpasangan.

\section{HASIL DAN PEMBAHASAN}

Data yang diperoleh kemudian diolah dengan menggunakan computer program SPSS dan disajikan dalam bentuk tabel frekuensi, dan tabel uji $\mathrm{t}$ sampel berpasangan. Adapun hasil penelitian diuraikan sebagai berikut:

Tabel 1 menunjukkan bahwa distribusi responden berdasarkan pendidikan dengan persentase tertinggi adalah SMA yaitu sebanyak 18 orang $(51,4 \%)$ Sedangkan persentase terendah adalah berpendidikan SD yaitu 3 orang $(8,6 \%)$.

Tabel 1. Distribusi Responden Berdasarkan Pendidikan Di Kelurahan Tobeleu Kecamatan Kota Ternate Utara Tahun 2019.

\begin{tabular}{ccc}
\hline Tingkat Pendidikan & $\mathrm{n}$ & $\%$ \\
\hline SD & 3 & 8.6 \\
SMP & 9 & 25.7 \\
SMA & 18 & 51.4 \\
Perguruan Tinggi & 5 & 14.3 \\
\hline Jumlah & 35 & 100
\end{tabular}

Sumber : Data Primer

Tabel 2. Distribusi Responden Berdasarkan Pekerjaan Di Kelurahan Tobeleu Kecamatan Kota Ternate Utara. Tahun 2019

\begin{tabular}{|c|c|c|}
\hline Pekerjaan & $\mathrm{n}$ & $\%$ \\
\hline PNS & 4 & 11.4 \\
\hline Pegawai Swasta & 11 & 31.4 \\
\hline Wiraswasta & 5 & 14.3 \\
\hline IRT & 15 & 42.9 \\
\hline Jumlah & 35 & 100 \\
\hline
\end{tabular}

Sumber : Data Primer

Tabel 2 menunjukkan bahwa distribusi responden berdasarkan pekerjaan dengan persentase tertinggi berada pada ibu yang bekerja sebagai Ibu Rumah Tangga yaitu sebanyak 15 orang $(42,9 \%)$ sedangkan persentase terendah berada pada ibu yang bekerja sebagai PNS yaitu 4 orang $(11,4 \%)$. 
Tabel 3. Distribusi Frekuensi Tingkat Kecemasan ibu Menghadapi Menopause Sebelum Penyuluhan Kelurahan Tobeleu Kecamatan Kota Ternate Utara Tahun 2019

\begin{tabular}{lcc}
\hline \multicolumn{1}{c}{ Tingkat Kecemasan } & $\mathrm{n}$ & $\%$ \\
\hline Tidak ada kecemasan & 4 & 11.4 \\
Kecemasan Ringan & 4 & 11.4 \\
Kecemasan Sedang & 13 & 37.1 \\
Kecemasan Berat & 14 & 40.0 \\
\hline \multicolumn{1}{c}{ Jumlah } & 35 & 100
\end{tabular}

Sumber : Data Primer

Tabel 3 menunjukkan tingkat kecemasan ibu sebelum diberikan penyuluhan tentang menopause. Sebelum diberikan penyuluhan diketahui tingkat kecemasan ibu menghadapi menopause berat sebanyak 14 orang (40,0\%), tingkat kecemasan sedang sebanya 13 orang $(37,1 \%)$, tingkat kecemasan ringan dan tidak ada kecemasan menghadapi menopause hanya 4 orang $(11,4 \%)$.

Tabel 4. Distribusi Frekuensi Tingkat Kecemasan ibu Menghadapi Menopause Setelah Penyuluhan Kelurahan Tobeleu Kecamatan Kota Ternate Utara Tahun 2019

\begin{tabular}{lcc}
\hline \multicolumn{1}{c}{ Tingkat Kecemasan } & $\mathrm{n}$ & $\%$ \\
\hline Tidak ada kecemasan & 16 & 45.7 \\
Kecemasan Ringan & 13 & 37.1 \\
Kecemasan Sedang & 6 & 17.1 \\
Kecemasan Berat & 0 & 0 \\
\hline \multicolumn{1}{c}{ Jumlah } & 35 & 100
\end{tabular}

Sumber : Data Primer

Tabel. 4 menunjukkan tingkat kecemasan ibu setelah diberikan penyuluhan tentang menopause. Setelah diberikan penyuluhan diketahui tidak ada ibu yang mengalami kecemasan/ panik sebanyak 16 orang $(45,7 \%)$, sedangkan ibu yang mengalami tingkat kecemasan ringan ada 13 orang $(37,1$ $\%)$. Ibu yang mengalami tingkat kecemasan sedang hanya 6 orang $(17,1 \%)$. 
Tabel.5 Uji Normalitas Sebaran Data di Kelurahan Tobeleu Kecamatan Kota Ternate Utara

\begin{tabular}{cccc}
\hline Tingkat Kecemasan & Shapiro Wilk & $\mathrm{p}$ value & Hasil \\
\hline Sebelum penyuluhan & 0.943 & 0.067 & Normal \\
\hline Setelah penyuluhan & 0.943 & 0.071 & Normal \\
\hline
\end{tabular}

Sumber : Data Primer

Berdasarkan pada tabel 5 di atas dapat diketahui bahwa tingkat kecemasan dalam menghadapi menopause pada pre test mempunyai sig. $0,067>0,05$ dan post test dengan sig. $0,071>0,05$. Hasil ini menunjukkan bahwa data pre test dan post test kecemasan dalam menghadapi menopause berdistribusi normal.

Tabel 6. Uji t Sampel Berpasangan Tingkat Kecemasan ibu dalam Menghadapi Menopause di Kelurahan Tobeleu Kecamatan Kota Ternate Utara

\begin{tabular}{lccc}
\hline \multicolumn{1}{c}{ Tingkat Kecemasan } & Mean & T Hitung & p value \\
\hline Pre Test & 43.86 & 7.425 & 0,000 \\
Post Test & 18.29 & & \\
\hline
\end{tabular}

Berdasarkan pada tabel 6 diketahui bahwa nilai rerata kecemasan ibu dalam menghadapi menopause sebelum dilakukan penyuluhan lebih besar daripada setelah dilakukan penyuluhan. Hal ini menunjukkan adanya penurunan tingkat kecemasan dalam menghadapi menopause setelah dilakukan penyuluhan tentang menopause. Hasil analisa dengan menggunakan uji t sampel berpasangan diperoleh nilai t hitung $=7,425$ dengan $\mathrm{p}$ value $0,000<\alpha=0,05$. Hal ini mempunyai arti bahwa terdapat perbedaan yang signifikan kecemasan ibu premenopause dalam menghadapi menopause sebelum dan sesudah dilakukan penyuluhan tentang menopause, sehingga hipotesis penelitian "ada pengaruh penyuluhhan tentang menopause terhadap tingkat kecemasan ibu menghadapi menopause di Kelurahan Tobeleu Kecamatan Kota Ternate Utara tahun 2018 terbukti kebenarannya.

Pembahasan penelitian yang bertujuan untuk mengetahui pengaruh penyuluhan terhadap tingkat kecemasan ibu dalam menghadapi menopause di Kelurahan 
Tobeleu Kecamatan Kota Ternate Utara adalah sebagai berikut :

1. Tingkat Kecemasan Ibu dalam Menghadapi Menopause Sebelum Penyuluhan

Kecemasan dapat teratasi jika ibu mempunyai pengetahuan sehingga lebih siap menghadapi menopause. Untuk meningkatkan pengetahuan ibu perlu mengikuti kegiatan pendidikan kesehatan tentang menopause yang karena dengan kegiatan tersebut dapat menambah informasi tentang menopause. Hal ini menyebabkan ibu lebih siap dalam menghadapi masa menopause, sehingga keluhan-keluhan yang dirasakannya menjelang menopause dapat teratasi dengan baik, yang berlanjut dapat terhindar dari kecemasan dibandingkan dengan wanita yang kurang pengetahuan tentang menopause.

Berdasarkan penelitian ini menunjukkan tingkat kecemasan ibu sebelum diberikan penyuluhan tentang menopause. Sebelum diberikan penyuluhan diketahui tingkat kecemasan ibu menghadapi menopause berat sebanyak 14 orang $(40,0 \%)$, tingkat kecemasan sedang sebanya 13 orang $(37,1 \%)$, tingkat kecemasan ringan dan tidak ada kecemasan menghadapi menopause hanya 4 orang $(11,4 \%)$.

Adanya keragaman dan perbedaan tingkat kecemasan ibu dalam menghadapi menopause dapat disebabkan oleh beberapa faktor. Menurut Nugraha (2007), tingkat kecemasan ibu dalam menghadapi menopause dipengaruhi oleh psikis, peran keluarga, informasi dan budaya. Psikis yaitu pikiran negatif mengenai menopause bahwa menopause adalah permulaan kemerosotan memasuki usia tua, hilangnya kualitas feminism dan seksual wanita (Wulandari. 2015)

2. Tingkat Kecemasan Ibu dalam Menghadapi Menopause Setelah Penyuluhan

Stuart dan Suddan (2004), menyatakan bahwa salah satu faktor penyebab timbulnya kecemasan adalah kurangnya pengetahuan responden tentang menopause. Pengetahuan berpengaruh terhadap tingkat kecemasan responden dalam menghadapi menopause dan pengetahuan akan meningkat jika diberi pendidikan kesehatan tentang menopause. Pendidikan kesehatan tentang menopause merupakan salah satu sumber informasi bagi responden sehingga tidak terjadi kecemasan dalam menghadapi 
menopause. Informasi yang diperoleh tentang suatu objek akan berpengaruh terhadap sikap objek tersebut (Wulandari, 2015).

Berdasarkan penelitian ini menunjukkan menunjukkan tingkat kecemasan ibu setelah diberikan penyuluhan tentang menopause. Setelah diberikan penyuluhan diketahui tidak ada ibu yang mengalami kecemasan/ panik sebanyak 16 orang $(45,7 \%)$, sedangkan ibu yang mengalami tingkat kecemasan ringan ada 13 orang $(37,1 \%)$. Ibu yang mengalami tingkat kecemasan sedang hanya 6 orang $(17,1 \%)$. Adanya keragaman tingkat kecemasan dalam menghadapi menopause meskipun sudah dilakukan penyuluhan tentang menopause disebabkan karena faktor dari individu.

Menurut Kasdu (2008), sikap dan kesiapan seseorang wanita dalam mempersiapkan dan mengatasi sesuatu hal yang terjadi antara individu yang satu dan yang lainnya berbeda-beda, seperti halnya kesiapan dalam menghadapi menopause. Hasil penelitian menunjukkan bahwa meskipun sudah dilakukan pendidikan kesehatan mengenai menopause tetapi masih terdapat ibu yang mengalami tingkat kecemasan sedang hanya 6 orang $(17,1 \%)$.

Menurut asumsi peneliti, hal ini disebabkan oleh tingkat pendidikan dari responden penelitian. Tingkat kecemasan seseorang dipengaruhi oleh pendidikan, dimana makin tinggi tingkat pendidikan seseorang, Makin mudah seseorang tersebut dalam menerima informasi, sehingga makin banyak pula pengetahuan yang dimiliki. Sebaliknya tingkat pendidikan yang kurang akan menghambat perkembangan sikap seseorang terhadap nilai yang diperkenalkan. Hasil penelitian juga menunjukkan bahwa setelah dilakukan penyuluhan tentang menopause terdapat 16 orang $(45,7 \%)$ tidak mengalami kecemasan. Hal ini disebabkan ibu telah mengetahui bahwa menopause merupakan peristiwa alamiah dan konsekuensi dari proses penuaan, menurunnya fungsi organ bahkan berhentinya produksi hormon estrogen. Ibu premenopause harus menghadapinya dengan penuh tawakal, keikhlasan, dan sikap positif. Ibu premenopause juga telah siap menghadapi gejolak-gejolak psikologis akibat menopause. 
3. Pengaruh Penyuluhan Tentang Menopause Terhadap Tingkat Kecemasan Ibu Menghadapi Menopause

Penyuluhan kesehatan sebagai bagian dalam promosi kesehatan diperlukan sebagai upaya meningkatkan pengetahuan, sikap dan tindakan terhadap kesehatan. Oleh karena itu, tentunya diperlukan upaya penyediaan informasi, yang merupakan bidang garapan penyuluhan kesehatan. Makna asli penyuluhan adalah pemberian penerangan dan informasi, maka setelah dilakukan penyuluhan kesehatan seharusnya akan terjadi peningkatan pengetahuan oleh masyarakat (Makahanap, dkk. 2015).

Berdasarkan hasil penelitian diketahui bahwa nilai rerata kecemasan ibu dalam menghadapi menopause sebelum dilakukan penyuluhan lebih besar daripada setelah dilakukan penyuluhan. Hal ini menunjukkan adanya penurunan tingkat kecemasan dalam menghadapi menopause setelah dilakukan penyuluhan tentang menopause. Hasil analisa dengan menggunakan uji t sampel berpasangan diperoleh nilai t hitung $=7,425$ dengan $p$ value $0,000<\alpha=0,05$. Hal ini mempunyai arti bahwa terdapat perbedaan yang signifikan kecemasan ibu premenopause dalam menghadapi menopause sebelum dan sesudah dilakukan penyuluhan tentang menopause, sehingga hipotesis penelitian “ada pengaruh penyuluhhan tentang menopause terhadap tingkat kecemasan ibu menghadapi menopause di Kelurahan Tobeleu Kecamatan Kota Ternate Utara tahun 2019 terbukti kebenarannya.

Hasil penelitian ini sejalan dengan penelitian Wulandari menunjukkan analisa dengan uji t sampel berpasangan diketahui bahwa penyuluhan tentang menopause mempunyai pengaruh terhadap kecemasan ibu dalam menghadapi menopause. Hal ini ditunjukkan dari nilai $\mathrm{t}$ hitung $=7,856>\mathrm{t}$ tabel $(1,694)$ dengan $\mathrm{p}$ value $0,000<\mathrm{a}$ $=0,05$ yang berarti penyuluhan tentang menopause mempunyai pengaruh signifikan terhadap kecemasan ibu pre menopause di Pedukuhan Dagaran Palbapang Bantul.

Sejalan pula dengan penelitian Suryati \& Suharni (2011) menunjukkan tingkat pengetahuan tentang menopause sebelum dan sesudah penyuluhan didapatkan nilai t sebesar 7,2 pada df 33 dengan taraf signifikansi (p) 0,000 berarti ada pengaruh penyuluhan tentang menopause 
terhadap tingkat pengetahuan ibu premenopause menghadapi menopause di Dusun Saman wilayah Puskesmas Sewon II Bantul Yogyakarta tahun 2011.

\section{SIMPULAN}

Berdasarkan hasil penelitian maka dapat disimpulkan bahwa:

1. Tingkat kecemasan ibu sebelum diberikan penyuluhan tentang menopause sebagian besar menunjukkan tingkat kecemasan ibu berat sebanyak 14 orang (40,0\%), tingkat kecemasan sedang sebanyak 13 orang $(37,1 \%)$, tingkat kecemasan ringan sebanyak 13 orang $(37,1 \%)$ dan tidak ada kecemasan menghadapi menopause hanya 4 orang $(11,4 \%)$.

2. Tingkat kecemasan ibu setelah diberikan penyuluhan tentang menopause sebagian besar tidak ada ibu yang mengalami kecemasan/ panik sebanyak 16 orang $(45,7 \%)$, sedangkan ibu yang mengalami tingkat kecemasan ringan ada 13 orang $(37,1 \%)$. Ibu yang mengalami tingkat kecemasan sedang hanya 6 orang $(17,1 \%)$.

3. Ada pengaruh penyuluhhan tentang menopause terhadap tingkat kecemasan ibu menghadapi menopause (p value $0,000<\alpha=0,05)$.

\section{UCAPAN TERIMA KASIH}

Program Studi Diploma IV Kebidanan Politeknik Kesehatan Kementerian Kesehatan Ternate.

\section{DAFTAR RUJUKAN}

Abbottabad, J Ayub Med Coll. 2010. Common Trend of Antibiotics Usage In A Tertiary Care Hospital Of Peshawar, Pakistan

Barbieri, R.L. 2009. Female infertility: Reproductive endocrinology physiology, pathophysiology, and clinical management. (5th ed.), Philadelphia: Elsevier Saunders.

Dahlan MS. 2006. Besar Sampel dalam Penelitian Kedokteran dan Kesehatan.Jakarta : PT ARKANS; 14-15; 59-63.

Depkes RI. 2009. Pedoman Pengelola an Kegiatan Kesehatan di Kelompok Lanjut Usia. Jakarta: Depkes RI

Depkes RI. 2013. Riset Kesehatan Dasar. Jakarta: Badan Penelitian dan pengembangan Kesehatan Kementrian Kesehatan RI

Hurlock, E.B. 2004. Psikologi Perkembangan. $\quad 5^{\text {th }}$ edition. Erlangga: Jakarta

Indarti. 2011. Panduan Kesehatan Wanita. 
Jakarta Pustaka Pembangunan Swadaya

Isyana, A.N.2017.Faktor yang Mempengaruhi Tingkat Kecemasan Ibu Perimenopause.The Journal of Public Health.Unairpress:Surabaya

Kasdu, Dini. 2002. Kiat Sehat dan Bahagia di Usia Menopause. Pustaka pembangunan Swadaya Nusantara; Jakarta.

K., Lewis, F.M., \& Rimer, B.K. 2008. Health behavior \& health education: Theory, research, and practice. (2nd ed.), San Fransisco: Jossey-Bass Publisher.

Lestari, D.2010. Seluk Beluk Menopause.Jogjakarta: Gerai Ilmu

Makahanap, dkk. 2015. Pengaruh penyuluhan kesehatan mengenai menopause terhadap tingkat pengetahuan ibu usia 45-55 tahun di wilayah kerja puskesmas tonsea lama Kecamatan tondano utara. Universitas Sam Ratulangi Manado

Manuaba. 2009. Memahami Kesehatan Reproduksi Wanita. Jakarta: EGC.

Nirmala. 2013.Hidup Sehat dengan Menopause. Jakarta : Buku Populer Nirmala

Nusantoro,D.C. 2015, Hubungan Antara Tingkat Pengetahuan wanita
Premenopause Tentang Menopause dengan Kecemasan dalam Menghadapi Menopause di Pedukuhan Semampir Wetan Pedukuhan Tambakrejo Kecamatan Tempel Kabupaten Sleman. FKUGM:Yogyakarta

O' Brien, P. 1994. Menghadapi Masa Menopause Dengan Penuh Kebahagiaan. Alih Bahasa: Rita, S. S. Jakarta: Binarupa Akasara.

Purwoastuti, E. 2008, Menopause Siapa Takut?, Kanisius: Yogyakarta.

Reitz, R. 1993.Menopause. Jakarta : PT. Bumi Aksara

Retnowati. 2010. Tetap Bergairah Dalam Menghadapi Menopause. Fakultas Psikologi UGM; Yogyakarta.

Santrock, J.W. 2002. Life-Span Development. Perkembangan Masa Hidup. Edisi Kelima. Jilid 2. Alih Bahasa: Damanik, J., dan Chusairi, A. Jakarta: Erlangga

Suparto, 2010,Sehat Menjelang Usia Lanjut , Bandung: PT Remaja Rosdakarya.

Suryati \& Suharni. 2011. Pengaruh Penyuluhan Tentang Menopause Terhadap Tingkat Pengetahuan Ibu Premenopause Menghadapi Menopause di Dusun Saman Wilayah Puskesmas Sewon II Bantul yogyakarta. STIK 'Aisyiyah 
Yogyakarta.

Wirakusumah, Emma S. 2013,Menopause, Gramedia Pustaka Utama, Jakarta.

Wulandari. 2015. Pengaruh Penyuluhan Tentang Menopause Terhadap Tingkat Kecemasan Ibu Menghadapi Menopause Di Pedukuhan Dagaran Palbapang Bantul Kabupaten Bantul Yogyakarta Tahun 2015. STIK 'Aisyiyah Yogyakarta

Yatim,Faisal. 2001.Haid Tidak Wajar dan Menopause. Jakarta : Pustaka Populer Obor. 
